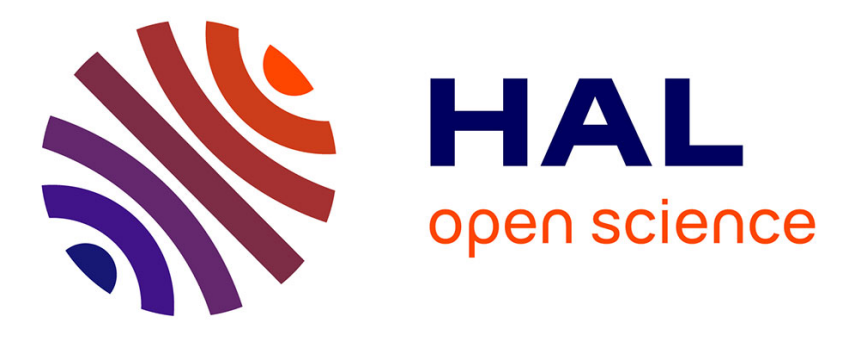

\title{
Paul Tessier facial reconstruction in 1970 Iran, a series of post-noma defects
}

François Simon, S Anthony Wolfe, Benjamin Guichard, Chloé Bertolus, Roman Hossein Khonsari

\section{To cite this version:}

François Simon, S Anthony Wolfe, Benjamin Guichard, Chloé Bertolus, Roman Hossein Khonsari. Paul Tessier facial reconstruction in 1970 Iran, a series of post-noma defects. Journal of CranioMaxillofacial Surgery, 2015, pp.1-28. 10.1016/j.jcms.2015.02.014 . hal-01132871

\section{HAL Id: hal-01132871 https://hal.sorbonne-universite.fr/hal-01132871}

Submitted on 18 Mar 2015

HAL is a multi-disciplinary open access archive for the deposit and dissemination of scientific research documents, whether they are published or not. The documents may come from teaching and research institutions in France or abroad, or from public or private research centers.
L'archive ouverte pluridisciplinaire HAL, est destinée au dépôt et à la diffusion de documents scientifiques de niveau recherche, publiés ou non, émanant des établissements d'enseignement et de recherche français ou étrangers, des laboratoires publics ou privés. 


\section{Paul Tessier facial reconstruction in 1970 Iran, a series of post-noma defects}

\section{Authors:}

François SIMON ${ }^{1}$; S Anthony WOLFE $^{2}$; Benjamin GUICHARD ${ }^{3}$; Chloé BERTOLUS ${ }^{1}$; Roman Hossein KHONSARI ${ }^{1}$

${ }^{1}$ : AP-HP, Hôpital Pitié-Salpêtrière, Service de chirurgie maxillo-faciale, Paris, F-75013, France ; UPMC Univ Paris 06, F-75005, Paris, France ;

2 : Plastic and Reconstructive Surgery, Miami Children’s Hospital, 3100 SW 62 Avenue, ACB \#2230, Miami FL

${ }^{3}$ : Hôpital Charles-Nicolle, Service de chirurgie maxillo-faciale, Rouen, F-76038, France ; Université de Rouen, Rouen, France ;

\section{Corresponding author:}

François SIMON, MD

AP-HP, Hôpital Pitié-Salpêtrière, Service de chirurgie maxillo-faciale

47-83 Boulevard de l'Hôpital, 75013 Paris (France)

$+33685967200$

fsimon05@gmail.com 


\begin{abstract}
Background: Paul Tessier was a pioneering plastic surgeon who founded craniofacial surgery and had an international influence in the field of reconstructive surgery. We reviewed his techniques in the reconstruction of post-noma defects in Iran in the late 1970s.

Patients and Methods: We studied a series of 23 patients operated on by Tessier from 1974 to 1978 in Iran (property of Association Française des Chirurgiens de la Face). They all suffered from noma in childhood with major facial defects.

Results: Ten suffered from simple lip and cheek defects, nine also from nose defects and four from extensive facial defects. Abbe flaps were used in 15 patients to reconstruct the lips completed by commissuroplasty in six patients. Nose defects were reconstructed with nasofrontal flaps (ten cases). The outer cheek was reconstructed with a rotation flap (four cases), or with a frontotemporal flap (six cases). The inner cheek was reconstructed using a Barron-Tessier myocutaneous flap (ten cases). Of the 23 patients, flap necrosis occurred in five cases.

Conclusions: Tessier was a pioneering plastic surgeon who used local flaps to reconstruct these important facial defects. He had a high rate of success, although nowadays local flaps are commonly replaced by free flaps.
\end{abstract}

Keywords: Barron-Tessier flap; Iran; noma; Paul Tessier; reconstruction 
Introduction: Paul Tessier was a leading craniofacial surgeon who came to Iran in the late 1970s to reconstruct post-noma defects. He was invited by the Shah to apply his innovative techniques of facial reconstruction and restore some humanity after the extensive mutilation caused by noma. The invitation of world-known physicians to Iran was also part of a greater effort to boost and modernize Iran's health system (Wolfe, 1997; Watts, 2008; Guichard et al., 2013). Noma (from the Greek "'to devour"”) is a severe infectious disease usually found in extreme sanitary conditions, such as many areas of rural Iran in the 1960s (Ronaghy and Nasr, 1970; Asadi-Lari et al., 2004; Movahedi et al., 2009). Often preceded by a systemic infection (such as measles or malaria), it develops at a young age (peak age 1-4 years) and in conditions of malnutrition, poor local hygiene and medical isolation (Tempest, 1966; Bourgeois and Leclercq, 1999; Baratti-Mayer et al., 2003; Marck, 2003; Enwonwu et al., 2006; Feller et al., 2013). Studies have established a link between noma and the country's economic development, especially the enforcement of public health policies (Bourgeois and Leclercq, 1999; Marck, 2003; Enwonwu et al., 2006). The disease mechanism is not clearly understood but multiple factors interact from bacterial or viral infection to capillary and arterial microthrombosis (Baratti-Mayer et al., 2003). Noma starts as a gingival ulcer and quickly evolves into major facial gangrene and death in $80 \%$ of cases (Tempest, 1966; Bourgeois and Leclercq, 1999; Baratti-Mayer et al., 2003; Marck, 2003; Enwonwu et al., 2006). The infection can be treated at an early stage with broad-spectrum antibiotics but most patients seek medical assistance at a late stage when extensive facial defects can only be reconstructed by surgery (Bourgeois and Leclercq, 1999; Baratti-Mayer et al., 2003; Enwonwu et al., 2006).

Long term defects are very difficult to treat due to the fibrous and retracting scars which add to the initial tissue loss, mainly of the mouth and cheek. Patients suffer from social isolation following the great disfigurement and important functional complications, mainly 
maxillomandibular constriction due to muscular fibrosis or sometimes bony ankylosis and fusion (Tempest, 1966; Bourgeois and Leclercq, 1999; Baratti-Mayer et al., 2003; Marck, 2003; Enwonwu et al., 2006). Other consequences include severe dental malposition, salivary incontinence or speech impairment. Surgical reconstruction usually requires many procedures with stage by stage planning using local flaps and increasingly nowadays, free flaps (Tempest, 1966; Montandon et al., 1991; Marck and de Bruijn, 1999; Giessler and Schmidt, 2003; Marck, 2003).

Material and methods: We recovered documents comprising accounts of consultation and surgical procedures (from the Tessier collection (Guichard et al., 2013), property of the Association Française des Chirurgiens de la Face), concerning a series of 23 patients operated on by Paul Tessier for post-noma defects in Iran (Tehran) in the late 1970s. Tessier wrote in detail (in a typed or handwritten format) the clinical description of the defects and each surgical technique used for the facial reconstruction, all cases had photographs of the original defects and sometimes of post-reconstruction. He was especially meticulous and from the very first consultation anticipated and planned out all the following steps (Fig. 1). During the procedures themselves he was also very precise in his notes and discussed step by step the different solutions to each problem he encountered.

From these documents, we classified the different types of defects using the Montandon classification (Montandon et al., 1991) (Fig. 2), thus enabling us to separate patients with central (type II or III) or lateral (type I or IV) defects. We also studied the different surgical techniques sorting them according to the anatomical structure being reconstructed. Thereby we compared the techniques, their frequency and effectiveness first between themselves and then finally to the techniques described nowadays in the literature.

Results: A series of 14 female and nine male patients were operated on in Tehran from May 1974 to September 1978 with a mean age of 24 years (range: 6-54) at the time of surgery. 
The age at which the noma infection occurred was recorded in only nine cases, with a mean age of 7 years (range: 2-17). Based on this average, the year in which noma was contracted was calculated for all patients and showed a peak of incidence in the 1960s (from 1931 to 1973). All patients came from isolated rural areas and medical assistance for defect reconstruction was sometimes only sought years after the initial infection. The defects were classified using the Montandon classification (Fig. 2) showing a majority of type I (ten, 44\%) affecting the lip and cheek and of type II (nine, 39\%) affecting the upper lip and nose. Only one case (4\%) was of type III affecting the lower lip and chin and three patients (13\%) were type IV suffering from extensive facial defects. The defects were always unilateral, 12 on the left and 11 on the right (Table 1). Half the patients $(n=12,52 \%)$ suffered from nose defects (Table 2). Up to seven had severe maxillomandibular constriction, due to bony fusion in one case (mandible to zygoma) and masseter fibrosis in the others. Another seven patients were found to have important bone defects (premaxilla in six cases and mandible in the other), one type IV patient had extensive premaxilla, zygoma, ethmoid and orbital floor bone defects.

As many as 13 patients had previously been unsuccessfully reconstructed using tube pedicles which were sometimes kept by Tessier for vestibular reconstruction but otherwise always removed. Indeed, Tessier considered that they were useless for the reconstruction (neither functional nor esthetic) and hampered his own reconstruction model. Using solely local flaps and an average of three procedures per patient, all the reconstructions were successful (including patients after secondary surgery for partial flap necrosis), although no long-term follow-up was available. Tracheotomy was necessary in two cases. Tessier's preferred reconstruction technique for each anatomical structure can be found in Table 3 .

Concerning lip reconstruction, Tessier chose the heterolabial Abbe flap in 15 patients, mainly for the upper lip, completed by commissuroplasty in six patients. Masseter flaps were also used in four cases, when the muscle was strong enough and non-atrophic, for both the upper 
and lower lip and a bilateral nasogenian flap for the upper lip was used once. When a frontotemporal flap was used for cheek reconstruction, Tessier also used it for the lips in four cases. To reconstruct a total or subtotal upper lip, Tessier combined a heterolabial Abbe flap and a cheek flap.

The nose was almost always reconstructed with nasofrontal flaps (ten cases) to remodel all types of defects ranging from the columella to the ala or the nose tip. The dorsum was reconstructed with iliac bone grafts in three cases and the nose floor or anterior palate were reconstructed with bone grafts (six cases) and septal grafts (three cases). When dealing with extensive type IV defects ranging from the cheek to the ala, the outer lining flap was often used to complement the reconstruction.

The outer cheek was reconstructed with a rotation flap (four cases), or with a frontotemporal flap (six cases), which was also used to correct the lower lip when possible. Submental island flaps were used twice and a retro-auricular-mastoidian flap and a direct left interior arm flap (Kong Bok, 1981) were used once. The inner cheek was reconstructed mainly using Barron-Tessier myocutaneous flaps (Fig. 3) for important defects (ten cases) and with mucosal flap in two less important cases.

Bone grafts were used in ten cases to support the soft tissue flaps and were always taken from the iliac bone mainly for premaxilla reconstruction. Skin grafts were also used in 13 cases to correct frontotemporal and nasofrontal flap harvesting sites.

Constriction was successfully treated in all cases, mostly by excision of masseter fibrosis and in one case by mandibular osteotomy due to bony fusion between the coronoid process and the zygoma. Teeth were extracted when necessary and a Le Fort I osteotomy was carried out in one case to correct a severe maxillary retrusion.

Out of the 23 patients, partial flap necrosis occurred in five cases and only concerned the cheek reconstruction, Barron-Tessier flaps had been used in four of the cases and the direct 
interior arm flap. A new procedure was necessary in two cases and the cheek was reconstructed using a frontotemporal and submental island flap.

Precise description of the surgical procedure is given in three cases: a patient with a central type II defect (case A, Fig. 3), with a lateral type IV defect (case B, Fig. 4) and lastly with another challenging type IV defect which was, in Tessier's own words “"la plus importante reconstruction hémi-faciale que j'ai entreprise en un seul temps'”, (the largest hemi-facial reconstruction that I have undertaken in a single stage; case C, Fig. 2 and 5).

Case A, a type II 19-year-old patient suffered important lesions to the upper lip, left corner of the mouth and nose, with columella, left ala, nose tip and dorsum defects. The patient had benefited at a younger age from numerous surgical procedures using tubed pedicle flaps which had to be replaced. Tessier first reconstructed the lip using a heterolabial flap for the left upper lip and the nose with a nasofrontal flap, reinforced by a bone graft. Skin was later grafted to the frontal donor-site. In a second stage, the patient benefited from a left commissuroplasty, Z-plasties of the scars and excision of excess tissue. In a final stage conchal cartilage graft to the left ala and Le Fort I osteotomy to correct maxillary retrusion was planned and the reconstruction was complete after five procedures.

Case B, a type IV 17-year-old patient also suffered from extensive noma sequellae with up to five attempted reconstructions using tube pedicle flaps, resulting in extensive cheek fibrosis continuing in the left lower and upper lip and major maxillomandibular constriction. The tube pedicle flaps were first removed by Tessier who then released the constriction with excision of masseter fibrosis. The left lip and corner of mouth were reconstructed using a masseter flap, the outer cheek using a frontotemporal flap and the inner cheek using a Barron-Tessier myocutaneous flap. Skin was grafted to the frontotemporal donor-site and the reconstruction was complete after two procedures. 
Case $\mathrm{C}$ was a 22-year-old patient with a complex type IV defect of the left side of the face with important cheek and nose defects (ala, columella) and severe constriction but most importantly a complete destruction of the left maxillary bone (including the orbital floor) and induced deformity of the left mandible. Extensive excision of scar tissue in the cheek and osteotomy of the mandible were necessary to partially lift the constriction. Tessier decided on a bold one-stage reconstruction using a temporal muscle flap reinforced by a fragment of the coronoid process to reconstruct the orbital floor (as described by Tessier in Fig. 5) and four different cutaneous local flaps to reconstruct the cheek and nose. A frontal flap was used to create a lateral nasal wall and a right frontotemporal flap to shape the nose. The cheek was reconstructed with a Barron-Tessier cervical flap for the inner lining and a left frontotemporal flap for the outer lining and finally skin was grafted to the large frontal donorsite. In a second stage Tessier grafted iliac bone to the maxillary and mandibular defects and the reconstruction was complete after four procedures.

Discussion: Tessier was an innovative surgeon who believed that all facial defects could be reconstructed using local or regional flaps after precise planning, following the precept of craniofacial autarchy (meaning that he considered the head and neck to be self-sufficient for reconstruction). Most of the techniques he introduced are still widely used today (Wolfe, 1997). All the previous reconstruction attempts in this series consisted of unsuccessful tubed pedicles and Tessier helped to develop the use of local flaps as an excellent functional and aesthetic solution to facial defects (Tempest, 1966; Adekeye and Ord, 1983).

The study of patient defects enables us, like other authors (Tempest, 1966; Adams-Ray and James, 1992; Pittet et al., 2001; Giessler et al., 2005), to distinguish two main reconstruction issues, in central defects with the nose and premaxilla (type II) and in lateral defects with the cheek and jaw constriction (type I and IV). The lip and especially the upper lip was almost always concerned in both reconstructions. 
The lip was most often repaired with a heterolabial flap and commissuroplasty when necessary. This is consistent with most authors as it is the way to best preserve the lip fullness with continence and aesthetic result (Tempest, 1966; Montandon et al., 1991; Adams-Ray and James, 1992). In lateral defects Tessier often used tissue from the cheek to complete reconstruction of the lip, using either the outer lining (frontotemporal or cheek island or rotation flap) or the masseter muscle itself. This was an innovative technique which gave muscle support and thickness to a mutilated corner of mouth as in facial paralysis rehabilitation (Sawhney, 1977; Conley and Gullane, 1978; Demir et al., 2001). Also some teams now prefer the use of free flaps (mostly forearm) to reconstruct large defects of the lip, the functional results, especially continence, are always disappointing compared with muscle or heterolabial flaps (Montandon et al., 1991; Giessler and Schmidt, 2003; Giessler et al., 2007). The use of the nasofrontal flap for the reconstruction of the nose has also been widely used in other teams in the 1970s and nowadays with excellent aesthetic results as can be seen in case A (Tempest, 1966; Montandon et al., 1991; Dean and Magee, 1997). Indeed no other local or free flap enables such an easy and effective reconstruction of the complex shape of the nose.

Repairing the cheek can be done with a large variety of methods either local or free flaps. Most authors agree that cheek reconstruction ideally needs double lining, although some teams use only one thick musculocutaneous flap (Adekeye et al., 1986; Adams-Ray and James, 1992; Ahmad et al., 2006; Kang et al., 2009). Tessier always used the Barron-Tessier flap to rebuild the inner lining of the cheek and mostly temporofrontal rotation flaps for the outer lining. When possible he did a slit masseter transposition to the corner of the mouth as an intermediate layer for lip fullness as discussed previously. Tessier was one of the first to develop this local platysma island flap technique (Fig. 6) rather than other regional flaps with great donor-site morbidity such as the deltopectoral or inner arm flap (Kong Bok, 1981; 
Adekeye and Ord, 1983; Adekeye et al., 1986). This highly reliable flap has many advantages as it is very thin and comparable to native tissue, has no donor-site morbidity and is technically simple (Futrell et al., 1978; Cannon et al., 1982; Coleman et al., 1983; Hurwitz et al., 1983; Talmant, 1983; Tessier et al., 2011). The main drawback in this series was the partial necrosis where total reconstruction was needed in two cases (10\%) compared with 0-8\% in the literature (Futrell et al., 1978; Coleman et al., 1983; Talmant, 1983; Tessier et al., 2011). The use of local flaps for the outer lining of the cheek such as the frontotemporal or submental flap was more common and easily found in the literature (Tempest, 1966; Barthelemy et al., 2002; Behan et al., 2013). The comparison to the more recent techniques of cheek reconstruction using free flaps (mostly forearm or parascapular) seem to favor Tessier's simpler and more functional approach in native hospitals. Also, compared with radial forearm flaps which take three to four hours, the Barron-Tessier flap can be completed in one hour, which significantly reduces operation time. Different studies show a high short-term failure rate $(10 \%)$ and an important long-term complication rate due to the lack of appropriate follow-up, which show that the complexity of the procedures associated with suboptimal native hospital conditions render free flaps more perilous to use in post-noma defects (Montandon et al., 1991; Giessler and Schmidt, 2003; Giessler et al., 2007; Bouman et al., 2010).

Indeed the strategy varies depending on whether the patient is operated on in a native hospital and in a one-stage or multi-stage planned operation. When treating post-noma defects, Tessier followed Tempest's principle of "safe, sound and simple"" where the goal is to restore satisfactory function and especially limit constriction rather than multiply complex procedures trying to obtain a perfect aesthetic result (Tempest, 1966). This particularly makes sense because most procedures as is this series take place during missions in the native country with sometimes suboptimal conditions and very short follow-up. Some teams, on the contrary, 
prefer to have the patients travel to their hospital, enabling them to use more complex procedures such as free flaps in a more secure environment (Montandon et al., 1991; Pittet et al., 2001). Nowadays, more and more free flaps are being used in native countries while attempting one-stage free flap reconstructions (Dean and Magee, 1997), however, a noma follow-up study tends to confirm Tessier's approach and shows a long-term complication rate of $64 \%$ in free flaps and a significantly much higher rate of success with simple local procedures comparing different teams (Bouman et al., 2010).

The main limit of this series is the lack of long term follow-up especially concerning constriction which, as we have seen can reappear even after excellent initial results, although this is mainly due to a lack of physiotherapy (Bisseling et al., 2010; Bouman et al., 2010). This series of patients also emphasizes the sanitary situation in rural areas of Iran in the 1960s which was much more extreme than one could think of nowadays (Asadi-Lari et al., 2004; Movahedi et al., 2009). Although Tessier's work was greatly needed the main battle was in the prevention of the disease. Statistics of children under five, during noma's peak of incidence, give a very good indication of nutrition and general health. Most of the population lived in rural areas (62\% of the population in villages under 5000 inhabitants in 1970) with poor nutrition, lack of sanitation and understanding of basic health measures and isolated from medical assistance (Ronaghy and Nasr, 1970). Attempts to improve public health in rural areas started in 1964 with the creation of a "'health corps"” and in 1973 with the “"auxiliary health workers"” (Ronaghy and Nasr, 1970; Zeighami et al., 1977; Barzegar and Djazayery, 1981). The first were young doctors who spent a few years in rural areas instead of their military service. The auxiliary health workers were trained for a few months to treat basic medical conditions and were sent to live within communities in remote rural areas where physicians were absent (Zeighami et al., 1977; Barzegar and Djazayery, 1981). They were allowed to give basic medication (including antibiotics) and would refer more 
complicated cases to physicians in local towns. A 1981 study showed a decrease in the birthrate and of under-five death rates explained by better infant nutrition, such as earlier solid food supplementation instead of sole breast-feeding, and earlier disease treatment (Barzegar and Djazayery, 1981).

Conclusion: This paper shows the importance of planning in the reconstruction of post-noma defects. Tessier carefully anticipated all the stages using simple local flaps which did not require optimal medical conditions. He also preferred to operate in native Iranian hospitals (although he sometimes had patients brought to France) limiting the reconstruction to a few surgical stages which required short follow-up. This strategy proved to be successful in all cases of these series although the reconstruction of the cheek proved to be challenging with some partial necrosis of his Barron-Tessier platysma flaps. Moreover, the cases emphasize the destructive aspect of this disease and its link to extreme poverty, especially malnutrition and protein depletion. Its occurrence in Iran, a country which has nowadays a developed health system and strong health statistics for children under five, shows the efforts that have been made since the peak of incidence of these cases in the 1960s. 


\section{Acknowledgement}

The authors would like to express their sincere gratitude to the Association Française des Chirurgiens de la Face (AFCF) for granting access to the documents and photos of the Tessier Collection (Centre Hospitalo-Universitaire d'Amiens, Université de Picardie).

\section{Conflict of interest statement}

The authors do not have any commercial or other association that might pose a conflict of interest.

The authors did not have any financial support to write this paper. 


\section{References}

Adams-Ray, W. E. and J. H. James: Cancrum oris: functional and cosmetic reconstruction in patients with ankylosis of the jaws. Br J Plast Surg 45: 193-198, 1992

Adekeye, E. O. and R. A. Ord: Cancrum oris: principles of management and reconstructive surgery. J Maxillofac Surg 11: 160-170, 1983

Adekeye, E. O., K. M. Lavery and N. A. Nasser: The versatility of pectoralis major and latissimus dorsi myocutaneous flaps in the reconstruction of cancrum oris defects of children and adolescents. J Maxillofac Surg 14: 99-102, 1986

Ahmad, Q. G., S. Navadgi, R. Agarwal, H. Kanhere, K. P. Shetty and R. Prasad: Bipaddle pectoralis major myocutaneous flap in reconstructing full thickness defects of cheek: a review of 47 cases. J Plast Reconstr Aesthet Surg 59: 166-173, 2006

Asadi-Lari, M., A. A. Sayyari, M. E. Akbari and D. Gray: Public health improvement in Iran-lessons from the last 20 years. Public Health 118: 395-402, 2004

Baratti-Mayer, D., B. Pittet, D. Montandon, I. Bolivar, J. E. Bornand, S. Hugonnet, et al.: Noma: an “'infectious”" disease of unknown aetiology. Lancet Infect Dis 3: 419-431, 2003

Barthelemy, I., D. Martin, J. P. Sannajust, K. Marck, V. Pistre and J. M. Mondie: Prefabricated superficial temporal fascia flap combined with a submental flap in noma surgery. Plast Reconstr Surg 109: 936-940; discussion 941-932, 2002

Barzegar, M. A. and A. Djazayery: Evaluation of rural primary health care services in Iran: report on vital statistics in West Azarbaijan. Am J Public Health 71: 739-742, 1981

Behan, F. C., W. M. Rozen, J. Wilson, S. Kapila, A. Sizeland and M. W. Findlay: The cervico-submental keystone island flap for locoregional head and neck reconstruction. J Plast Reconstr Aesthet Surg 66: 23-28, 2013 
Bisseling, P., J. Bruhn, T. Erdsach, A. M. Ettema, R. Sautter and S. J. Berge: Long-term results of trismus release in noma patients. Int J Oral Maxillofac Surg 39: 873-877, 2010

Bouman, M. A., K. W. Marck, J. E. Griep, R. E. Marck, M. A. Huijing and P. M. Werker: Early outcome of noma surgery. J Plast Reconstr Aesthet Surg 63: 2052-2056, 2010

Bourgeois, D. M. and M. H. Leclercq: The World Health Organization initiative on noma. Oral Dis 5: 172-174, 1999

Cannon, C. R., M. E. Johns, J. P. Atkins, Jr., W. M. Keane and R. W. Cantrell: Reconstruction of the oral cavity using the platysma myocutaneous flap. Arch Otolaryngol 108: 491-494, 1982

Coleman, J. J., 3rd, M. J. Jurkiewicz, F. Nahai and S. J. Mathes: The platysma musculocutaneous flap: experience with 24 cases. Plast Reconstr Surg 72: 315-323, 1983

Conley, J. and P. J. Gullane: The masseter muscle flap. Laryngoscope 88: 605-612, 1978

Dean, J. A. and W. Magee: One-stage reconstruction for defects caused by cancrum oris (noma). Ann Plast Surg 38: 29-35, 1997

Demir, Y., O. Latifoglu, R. Yavuzer and K. Atabay: Oral commissure reconstruction with split masseter muscle transposition and cheek skin flap. J Craniomaxillofac Surg 29: 351-354, 2001

Enwonwu, C. O., W. A. Falkler, Jr. and R. S. Phillips: Noma (cancrum oris). Lancet 368: $147-156,2006$

Feller, L., M. Altini, R. Chandran, R. A. Khammissa, J. N. Masipa, A. Mohamed, et al.: Noma (cancrum oris) in the South African context. J Oral Pathol Med 2013

Futrell, J. W., M. E. Johns, M. T. Edgerton, R. W. Cantrell and G. S. Fitz-Hugh: Platysma myocutaneous flap for intraoral reconstruction. Am J Surg 136: 504-507, 1978

Giessler, G. A. and A. B. Schmidt: Noma: experiences with a microvascular approach under West African conditions. Plast Reconstr Surg 112: 947-954; discussion 955-946, 2003 
Giessler, G. A., C. P. Cornelius, S. Suominen, A. Borsche, A. J. Fieger, A. B. Schmidt, et al.: Primary and secondary procedures in functional and aesthetic reconstruction of nomaassociated complex central facial defects. Plast Reconstr Surg 120: 134-143, 2007

Giessler, G. A., A. Fieger, C. P. Cornelius and A. B. Schmidt: Microsurgical reconstruction of noma-related facial defects with folded free flaps: an overview of 31 cases. Ann Plast Surg 55: $132-138,2005$

Guichard, B., J. Davrou, C. Neiva and B. Devauchelle: Midface osteotomies lines: evolution by Paul Tessier, the second Tessier classification. J Craniomaxillofac Surg 41: 504-515, 2013

Hurwitz, D. J., J. A. Rabson and J. W. Futrell: The anatomic basis for the platysma skin flap. Plast Reconstr Surg 72: 302-314, 1983

Kang, S. H., W. Nam, I. H. Cha and H. J. Kim: Double continuous radial forearm flap for the reconstruction of full-thickness buccal cheek defect. J Plast Reconstr Aesthet Surg 62: e95-96, 2009

Kong Bok, G.: Inner arm flap for the reconstruction of nasal and facial defects. Ann Plast Surg 6: 277-282, 1981

Marck, K. W.: A history of noma, the "Face of Poverty"”. Plast Reconstr Surg 111: 17021707,2003

Marck, K. W. and H. P. de Bruijn: Surgical treatment of noma. Oral Dis 5: 167-171, 1999 Montandon, D., C. Lehmann and N. Chami: The surgical treatment of noma. Plast Reconstr Surg 87: 76-86, 1991

Movahedi, M., B. Hajarizadeh, A. Rahimi, M. Arshinchi, K. Amirhosseini and A. A. Haghdoost: Trends and geographical inequalities of the main health indicators for rural Iran. Health Policy Plan 24: 229-237, 2009

Pittet, B., A. Jaquinet and D. Montandon: Clinical experience in the treatment of noma sequelae. J Craniofac Surg 12: 273-283, 2001 
Ronaghy, H. A. and K. Nasr: Medical problems of developing nations: an attempt to bring medical care to rural communities in Iran. Br Med J 1: 295-296, 1970

Sawhney, C. P.: Restoration of function to a lower lip reconstructed by flaps. Plast Reconstr Surg 60: 77-79, 1977

Talmant, J. C.: [Use of neck muscle in the correction of facial asymmetry. The Barron-Tessier flap]. Rev Stomatol Chir Maxillofac 84: 283-288, 1983

Tempest, M. N.: Cancrum oris. Br J Surg 53: 949-969, 1966

Tessier, P., D. C. Matthews, D. Kamerer, Jr., F. S. Ciminello, F. Gargano and S. A. Wolfe: Platysma-based myocutaneous clavicular island flap for intraoral reconstruction. Ann Plast Surg 67: S55-69, 2011

Watts, G.: Paul Tessier. Lancet 372: 368, 2008

Wolfe, S. A.: The influence of Paul Tessier on our current treatment of facial trauma, both in primary care and in the management of late sequelae. Clin Plast Surg 24: 515-518, 1997

Zeighami, B., E. Zeighami, H. A. Ronaghy and S. S. Russell: Acceptance of auxiliary health worker in rural Iran. Public Health Rep 92: 280-284, 1977 
Table 1. Defects according to Montandon type

\begin{tabular}{llllllll}
\hline Montandon & Constriction & Upper lip & Lower lip & COM* & Nose & Cheek & Bone \\
\hline Type I $n=10$ & $3(30 \%)$ & $10(100 \%)$ & $7(70 \%)$ & $7(70 \%)$ & $0(0 \%)$ & $7(100 \%)$ & $1(10 \%)$ \\
Type II $n=9$ & $0(0 \%)$ & $8(89 \%)$ & $3(33 \%)$ & $5(56 \%)$ & $9(100 \%)$ & $6(67 \%)$ & $4(45 \%)$ \\
Type III $n=1$ & $1(100 \%)$ & $1(100 \%)$ & $1(100 \%)$ & $1(100 \%)$ & $0(0 \%)$ & $1(100 \%)$ & $1(100 \%)$ \\
Type IV $n=3$ & $3(100 \%)$ & $3(100 \%)$ & $3(100 \%)$ & $3(100 \%)$ & $3(100 \%)$ & $3(100 \%)$ & $1(33 \%)$ \\
Overall $n=23$ & $7(30 \%)$ & $22(96 \%)$ & $14(61 \%)$ & $16(70 \%)$ & $12(52 \%)$ & $17(74 \%)$ & $7(30 \%)$ \\
\hline
\end{tabular}

*Corner of mouth

Table 2. Nose defects in 12 patients (type II and IV)

\begin{tabular}{l|llllll}
\hline & Floor & Ala & Columella & Tip & Septum & Dorsum \\
\hline$n$ & 8 & 11 & 8 & 6 & 1 & 2 \\
$\%$ & 67 & 92 & 67 & 50 & 8 & 16 \\
\hline
\end{tabular}

Table 3. Tessier preferred reconstruction flaps (by number of cases)

\begin{tabular}{lllll}
\hline Lip & Nose & Outer cheek & Inner cheek & Bone \\
\hline Heterolabial (15) & Nasofrontal (10) & Frontotemporal (6) & BT* (10) & Iliac (10) \\
Commisuroplasty (6) & & Cheek rotation (4) & & \\
Masseter flap (4) & & Submental (2) & \\
Frontotemporal (4) & & & \\
\end{tabular}

*BT: Barron-Tessier 
Fig. 1: Example (case C) of the notes used by Tessier showing the careful anticipation and planning of the surgical stages. The entire project is written down during the first consultation with the patient. It is then discussed at each step of the reconstruction. This thoroughness certainly played an important role in Tessier's progress and success as a surgeon.

Fig. 2: Examples of post-noma defects using Montandon classification. Type I (upper left) limited to corner of the mouth and cheek; type II (lower left) upper lip and nose; type III (upper right) lower lip; type IV (lower right) extensive cheek defect including malar or orbital bone (case C)

Fig. 3: Case A, central defect (type II), upper lip reconstructed with heterolabial Abbe flap, nose with frontal flap. Secondary commissuroplaty and Z-plasties. Photos before and after reconstruction. Tessier's main concern in this case was the lip reconstruction, he considered in his initial assessment a masseter flap (as in case B), but preferred the Abbe flap so as to preserve the intact masseter muscle.

Fig. 4: Case B, lateral defect (type IV), lips reconstructed with masseter flap, inner cheek with Barron-Tessier flap, outer cheek with frontal-temporal flap. Photos before and after reconstruction. In his comments Tessier especially emphasized the use of the masseter flap saying that he was very pleased with the functional result.

Fig. 5: Orbital floor reconstruction using a temporal flap associated with a nasofrontal flap (Sketch by Francine Gourdin from the Tessier collection, AFCF), used in case C. Tessier makes comments on this procedure after the surgery comparing it to another patient (mainly 
on where to divide the temporal muscle and discussion of the viability of the pedicle). Once again, this is great insight into how a meticulous Tessier became an innovative surgeon.

Fig. 6: Barron-Tessier platysma myocutaneous island flap. Illustration (Tessier et al., 2011) showing the anatomy of the Barron-Tessier flap, blood brought by artery perforators and drained by superficial veins.

Fig. 7: Translation of Fig. 1 (to be made available online). 
CONSULTATION de FEV. 77

Age de 2 ans : infection type NOMA

$\mathrm{Br}$. thérapeutique par acide?

1973 - tentative de reconstruction par lambeau tubulé

Constriction des mâchoires

Palais : déficit sub-total

Max. G. : mutilation totale étendue au malaire

Max. D. : fortement dévié à G.

Mandib. déviée

distordue à G.

endognathie $\mathrm{G}$.

Orbite G. : déficit du plancher globe - prolapsus

diplopie

P.I.G. : semble à peu près intacte mais est fortement rétractée par absence de R.I.O. elle disparait derrièreune redondance du tube

$\mathrm{Nez}$ : mutilation G. et columelle

mutilation cloison

Pointe intacte

$$
\text { aile D. }
$$

Cloison I.S.N.-G. : absente

Joue G. : mutilée peau et muqueuse

L.S.G. : mutilee

Commissure G. : mutilée

Vestibule : atrésie - partiellement reconstitué par ex-tube

PLAN

0 - Trachéotomie

1 - Résection reliquats tube

Conserver en profondeur une petite partie soit pour la joue, soit pour le plan oro-palatin.

2 - Ouvrir bouche

Extractions dentaires

3 - Dissection plan des narines D. , méat D. , palais D.

4 - Oeil : prolapsus

Orbite G. :

P.I.G. : enclavée

5 - Cloison I.S.N. et Naso-Palais : large lambeau frontal central en ilot sur oribite G.

6 - Vestibule Sup. Joue : FACE INTERNE Lambeau cervical

7 - S.O.G. :

Joue : FACE EXTERNE

L.S.-L.I. - Commissure :

Lambeau fronto-temporal G. y compris C.C. et un peu de sourcil

8 - Plancher orbite

9 - Hemi-nez G. :

10 - Front totalité

Lambeau muscle temporal plus corone

Lambeau frontal D. à pédicule $D$;

Greffe dermatome 

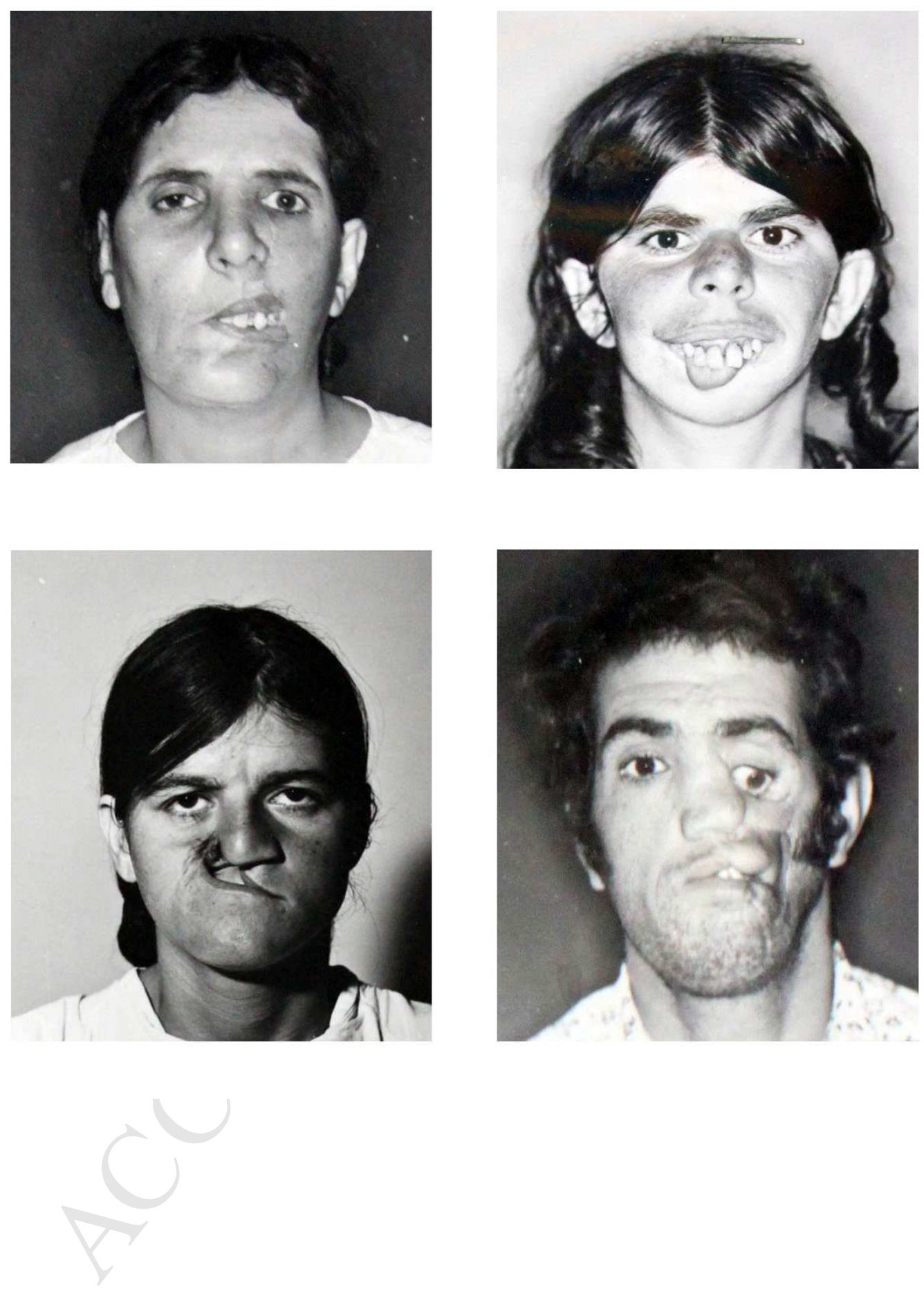

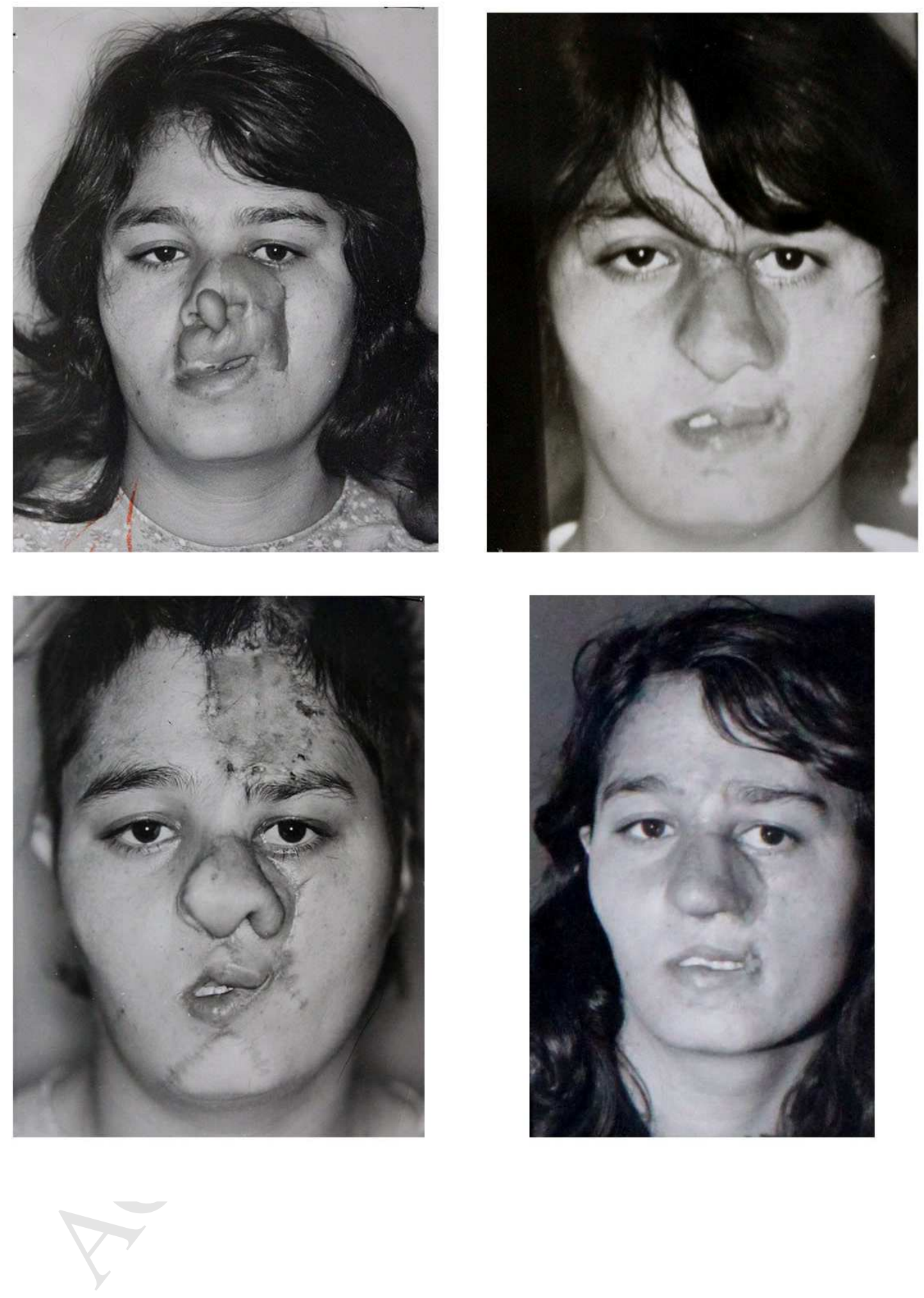

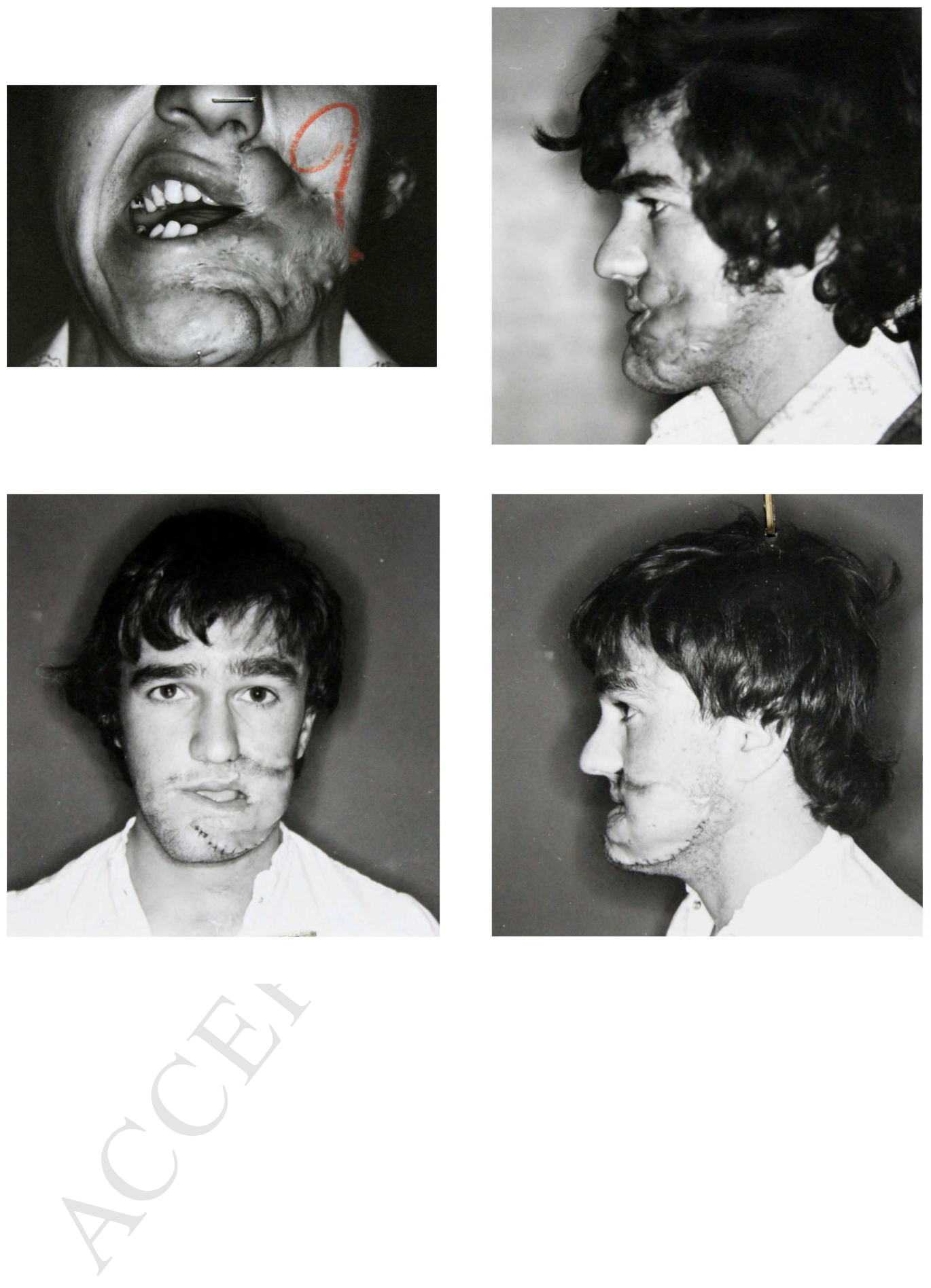


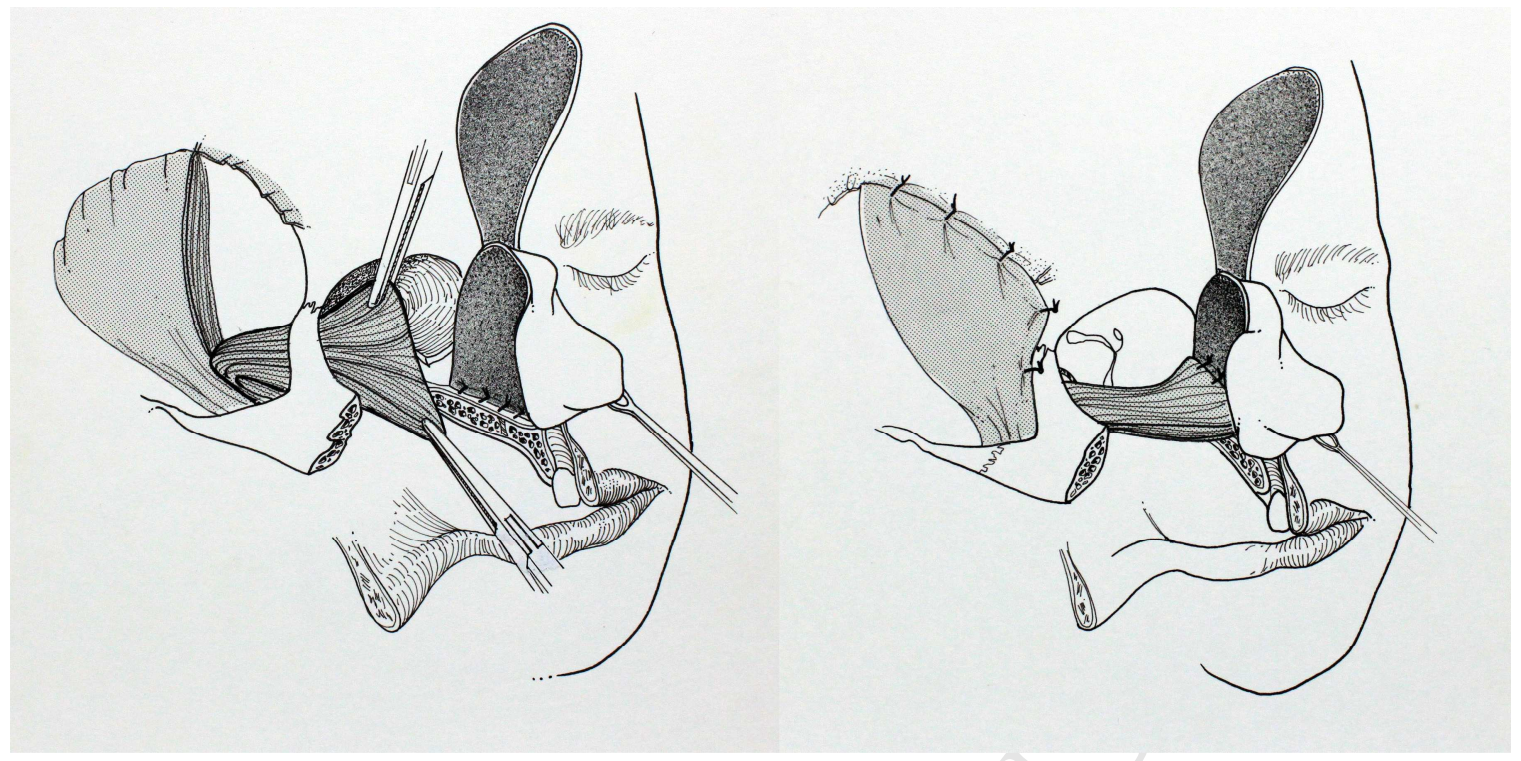




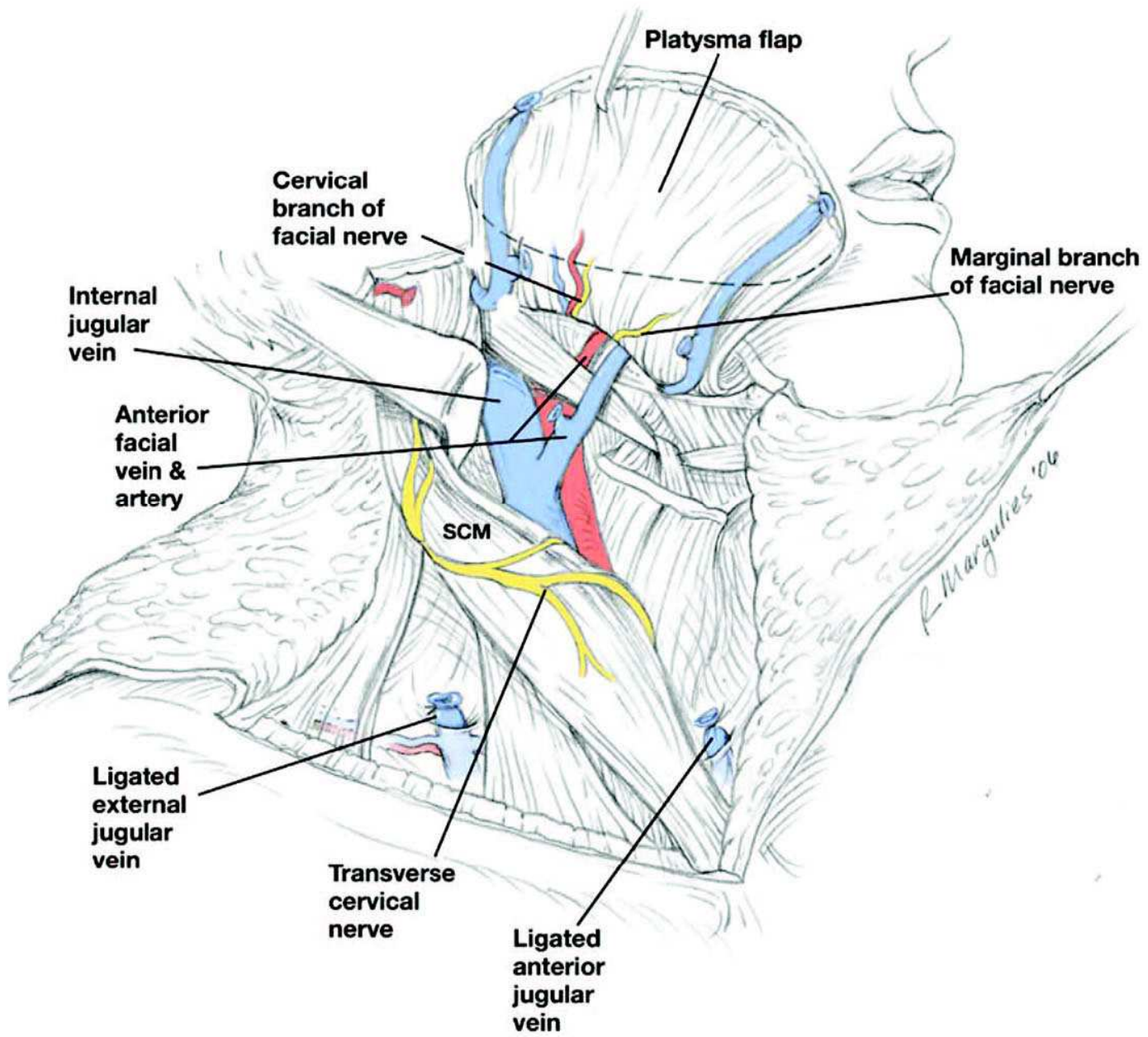


Feb. 1977 clinic

2 years old: noma-type infection treated by acid?

1973 - reconstruction attempt by tubed pedicle flap

Reduced opening of the jaws

Palate: partial defect

L. maxilla: total mutilation affecting the zygoma

R. maxilla: major left deviation

Lower jaw deviation

L. distorsion

$L$. endognathia

L. orbit: floor defect, eyeball prolapsus, diplopia

L. Tower eyelid: seems more or less intact but strongly retracted due to the absence of RIO; disappears under a the tube folds

Nose: L. mutilation and columella septum and R. alar mutilation tip intact

L. lateral wall of the nasal cavity: missing

L. cheek: skin and mucosa mutilation

L. upper 1ip: mutilation

L. commissure : mutilation

vestibule: atresia - partially reconstructed by ex-tubed pedicle

PLAN

0 - Tracheotomy

1 - Resection of the remnants of the tubed pedicle Keep a sma11 part of the deep layer for the cheek or for the palate

2 - open the mouth

Teeth extractions

3 - Dissection plane along the L. nostrils, L. meatus, L. palate

4 - Eye: prolapsus

L. orbit:

$L$ inferior eyelid: interlocked

5 - Lateral wall of the nasal cavity and nasopalatine region: wide central is 1 and forehead $f 1$ ap on $L$. orbit

6 - Sup. vestibu7e

cheek: internal side

7 - L. intraorbital area: cheek: external side upper - Lower Tip - commisure

8 - orbital floor

9 - L. side of the nose:

10- whole forehead

Neck flap

L. fronto-temporal flap including scalp and a fragment of eye-brov: Temporal muscle flap plus coronoid process $L$. Forehead flap with R. pedicle skin graft 
- Detailed account of Paul Tessier's approach to noma reconstruction;

- Importance of pre-operative step by step planning;

- Presence of noma in $20^{\text {th }}$ century Iran;

- Local flaps preferred to free flaps in facial reconstruction;

- Description of the Barron-Tessier myocutaneous flap for inner cheek reconstruction. 